\title{
Methanolic extract of Maytenus procumbens roots ameliorates erectile dysfunction in fructose-streptozotocin induced type 2 diabetic in rats
}

\author{
Nkosinathi D. Cele ${ }^{1}{ }^{*}$, Sihle E. Mabhida ${ }^{1,4}$, Thembeka Nyawob, ${ }^{2,5}$, Khanyisani Ziqubua, ${ }^{2}$, Sthandiwe E. Mazibuko- \\ Mbeje $^{2}$, Rebamang A. Mosa ${ }^{3}$, Andy R. Opoku ${ }^{1}$
}

\begin{abstract}
${ }^{1}$ Department of Biochemistry and Microbiology, Department of Agriculture, University of Zululand, Private Bag X1001, KwaDlangezwa 3886, RSA; melucy.cele@gmail.com; OpokuA@unizulu.ac.za; 2Biomedical Research and innovation platform (BRIP), South African Research Council, Tygerberg, 7505, RSA. sthamaz@gmail.com; ziqubukhanyisani@gmail.com; Sinenhlanhla.Mthembu@mrc.ac.za ${ }^{3}$ Department of Biochemistry Genetic and Microbiology, University of Pretoria, Private Bag X 20, Hatfield 0028, RSA. rebamang@gmail.com

${ }^{4}$ Department of Biotechnology, Faculty of Natural Science, University of the Western Cape, Private Bag X17, Bellville, Cape Town 7535, South Africa. sihlemabhida@gmail.com

${ }^{5}$ Division of Medical Physiology, Faculty of Medicine and Health Sciences, Stellenbosch University,

Tygerberg 7505, South Africa. Thembeka.Nyawo@mrc.ac.za
\end{abstract}

* Correspondence: OpokuA@unizulu.ac.za; Tel.: (+27 725574397)

\begin{abstract}
Erectile dysfunction (ED) due to diabetes mellitus remains difficult to treat despite advances in pharmacotherapeutic approaches in the field. Therefore, this study investigated the erectogenic effect of the methanolic extract of Maytenus procumbens roots on type 2 diabetes in rats. The fructose-streptozotocin model was used to induce type 2 diabetes-linked ED in male rats. The sexually active male Sprague Dawley rats were randomly divided into two major groups; normal group and high fructose fed group for 120 days. After 120 days, the high fructose fed group rats were given a single intraperitoneal injection of a freshly prepared streptozotocin solution (30 $\mathrm{mg} / \mathrm{kg}$ ).The diabetic ED rats were orally administered with the extract at $250 \mathrm{mg} / \mathrm{kg}$, daily for 28 days. The serum, brain and penile tissues were removed for biochemical analysis and protein expression. Increased testosterone level, mounting frequency, reduced blood glucose level and serum fructosamine content was observed after 28 days of treatment in diabetic rats. Methanolic extract also exhibited an inhibitory effect on arginase, AChE and ACE activities. The crude extract further downregulated proteins PDE-5, RhoA and increased expression of eNOS in the diabetic ED treated rats. The results obtained indicate that the methanolic extract of Maytenus procumbens roots ameliorates erectile dysfunction in type 2 diabetes induced erectile dysfunction in rats.
\end{abstract}

Keywords: Maytenus procumbens, Erectile dysfunction, Phosphodiesterase-5, cyclic guanosine monophosphate

\section{Introduction}

Erectile dysfunction (ED), the most common form of sexual dysfunction in sexually active men, is defined as the repeated inability to attain and maintain an adequate erection for satisfactory sexual intercourse. ED results from the loss of penile vascular and smooth muscle relaxation due multiple pathophysiological conditions such hypogonadism, hypertension, type 2 diabetes mellitus (T2D), etc. [1]. Approximately, 90\% of T2D men worldwide have been reported to have ED [2]. However, studies have shown that most clinicians do not enquire about sexual dysfunction during medical consultations and the prevalence of self-reported ED is also very low [3-5].

The pathogenesis through which T2D induces ED result from multiple factors, such as increased formation of advanced glycation end products (AGEs), oxidative stress, 
deficiency in the nitric oxide-cyclic guanosine monophosphate (NO-cGMP) signaling pathway and hypogonadism [6,7]. Among these factors, increased formation of AGEs is well-known to form covalent bonds with vascular collagen, causing a vascular thickening, reduced elasticity, endothelial dysfunction, increased vascular stiffness and subsequently results to ED [8]. Biomolecules such as testosterone, cGMP, NO, and acetylcholine (ACh) play a crucial role in penile erection processes [9]. For instance, the continuous decreased activity of nitric oxide synthase (NOS) which lead to a decreased NO production and depleted cGMP in the penile tissue and thus stimulate ED. Furthermore, literature also suggests that increased activities of acetylcholinesterase (AChE), arginase and angiotensin converting enzyme (ACE) are some causative agents of ED [10,11]. Studies have shown that insulin enhance the expression of endothelial nitric oxide synthase (eNOS) and subsequently stimulate NO production [12, 13]. These actions of insulin are inhibited by the upregulation of RhoA, a small GTPase which stimulates Rhokinase II (ROCK II) activity and directly inhibits expression of eNOS [14].

Several reports have clearly demonstrated that the use of hypoglycemic agents alone in T2D men do not improve sexual performance or libido [6, 15]. Hence, in an attempt to ameliorate this medical condition (ED), there is currently a rapid increase in the number of men's clinic. ED is currently treated with Sildenafil (Viagra) and Tadalafil (Cialis), which are all well known as PDE-5 inhibitors. However, these drugs are associated with adverse effects, and a large number of T2D men suffering from ED are refractory to these ED therapies [16]. Thus, the other approaches with less adverse effects could be employed in the discovery of new ED therapies, despite the broad research on ED therapy for many decades. The use of medicinal plant extracts, due to their multitarget nature, continue to attract attention of researchers in a bid to discover new drug regime against various ailments, including ED. Maytenus procumbens (Celastraceae), which is predominantly in KwaZulu Natal, South Africa, is commonly used by Zulu traditional healers to treat several diseases linked to sexual dysfunction in men [17, 18]. The ameliorative effect of methanol roots extract of M. procumbens on butanol induced testicular dysfunction in Sprague Dawley rats has been reported [18]. The ameliorative effect was associated with the regeneration of spermatogonia in the seminiferous tubules, increased serum testosterone, sperm count and mount frequency of the rats. However, the molecular mechanism associated with this ameliorated sexual performance remains to be elucidated. Thus, this study investigated the molecular mechanism of the methanolic extract of Maytenus procumbens roots in type 2 diabetes induced erectile dysfunction in Sprague Dawley rats.

\section{Results}

\subsection{Fasting blood glucose (FBG), Mounting frequency and serum testosterone levels}

Fasting blood glucose levels, mounting frequency and serum testosterone levels in diabetes induced ED rats after 28 days of treatment are shown in Table 1. The untreated diabetic ED rats presented with persistently higher fasting blood glucose levels. However, a slight decrease in the fasting blood glucose level, when compared to untreated diabetic ED group, was observed in diabetic ED rats treated with the extract for 28 days. Relatively lower testosterone levels, and mounting frequency when compared to the normal group, were also observed in untreated diabetic ED group. However, an increase $(p<0.001)$ in the tested parameters was evident in the animals treated with the extract.

Table 1. Effect of extract on FBG, mounting frequency and serum testosterone levels of the experimental rats 


\begin{tabular}{lcccc}
\hline Groups & $\begin{array}{c}\text { FBG } \\
\text { Baseline } \\
(\mathbf{m m o l} / \mathbf{L})\end{array}$ & $\begin{array}{c}\text { FBG } \\
\text { Week 21 } \\
(\mathbf{m m o l} / \mathbf{L})\end{array}$ & $\begin{array}{c}\text { Mount } \\
\text { frequency } \\
(\text { In 30 mins) }\end{array}$ & $\begin{array}{c}\text { Testosterone } \\
(\mathbf{n m o l} / \mathbf{L})\end{array}$ \\
\hline Normal control & $5.27 \pm 0.32$ & $5.28 \pm 0.05$ & $29 \pm 1.02$ & $5.66 \pm 0.17$ \\
Untreated Diabetic control & $12.77 \pm 0.56$ & $18.77 \pm 0.16$ & $09 \pm 1.00$ & $2.23 \pm 1.01$ \\
Diabetic + Cialis (5mg/kg) & $13.13 \pm 0.43$ & $15.46 \pm 0.08$ & $33 \pm 1.01$ & $8.69 \pm 2.94$ \\
Diabetic + RA-3 (100 mg/kg) & $16.37 \pm 0.54$ & $7.63 \pm 1.52^{* * *}$ & $31 \pm 3.11$ & $8.31 \pm 1.57$ \\
Diabetic + extract $(250 \mathrm{mg} / \mathrm{kg})$ & $11.71 \pm 0.03$ & $9.11 \pm 0.34$ & $42 \pm 1.20$ & $10.01 \pm 2.58^{* * * *}$ \\
ND. Control + extract $(250 \mathrm{mg} / \mathrm{kg})$ & $5.32 \pm 0.01$ & $5.12 \pm 0.02$ & $46 \pm 1.11$ & $11.93 \pm 2.61 * * *$ \\
\hline
\end{tabular}

\subsection{Serum fructosamine, protein thiol group content and uric acid}

Figure 2 shows the results of the effect of the extract on serum fructosamine, protein thiol group content and uric acid of the diabetes induced ED rats after 28 days of treatment. Elevated serum levels of fructosamine and lower protein thiol group were observed in the untreated diabetic animals or diabetic animals treated with Cialis, respectively, when compared to the normal control group. However, lower serum levels of the fructosamine content accompanied by a significant increase in protein thiol group concentrations were observed in the diabetic rats treated with the extract or RA-3 when compared to the untreated diabetic animals (Figure 2). Furthermore, a decreased uric acid level was also observed in the diabetic ED group treated with the extract or RA-3 when compared with an increase uric acid level in the untreated diabetic ED group.
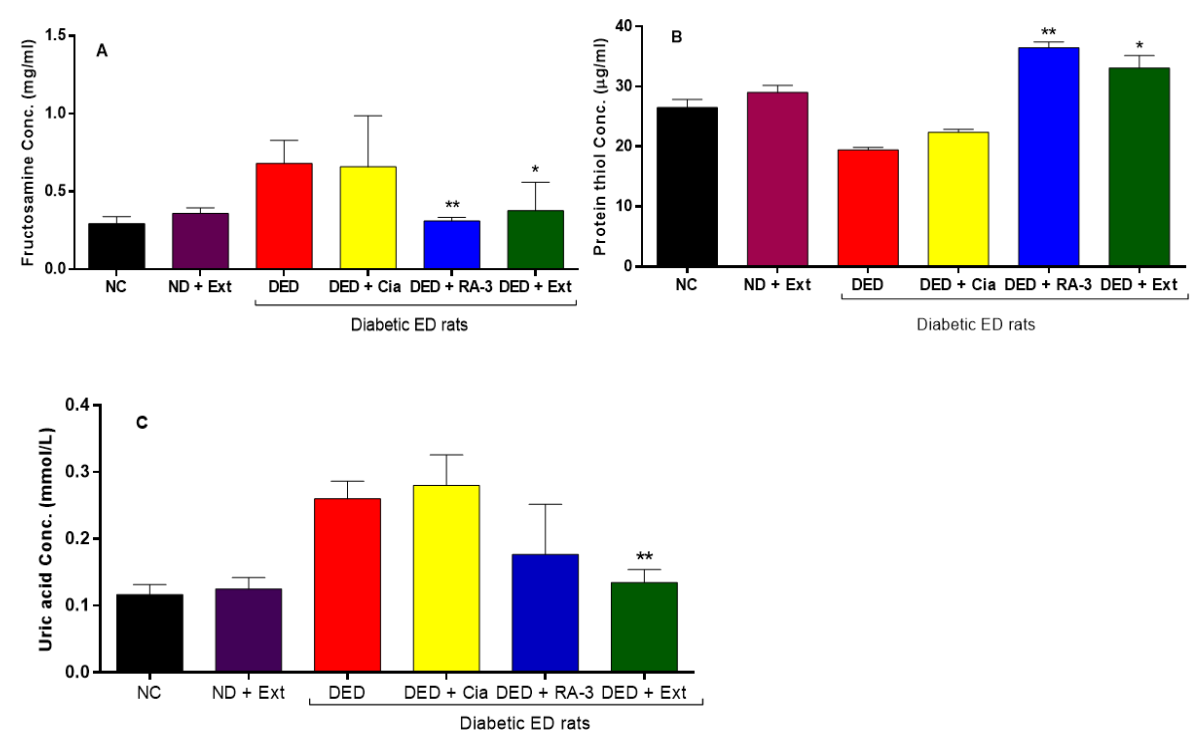

Figure 2. Effect of the methanol extract on fructosamine (A); protein thiol (B) contents and uric acid levels (C). Results are expressed as the mean $\pm \operatorname{SEM},(n=5) .{ }^{*} \mathrm{p}<0.01,{ }^{* *} \mathrm{p}<0.001 \mathrm{vs}$. Untreated diabetic induced ED control. NC - Normal control, ND + Ext - Nondiabetic + extract, DED - diabetic ED control, DED + Cia - Diabetic + Cialis, DED + RA-3 - Diabetic ED + RA-3, DED + Ext - Diabetic ED + extract. 
Table 2 shows the results of the effect of the extract on some serum antioxidant levels in the diabetes induced ED rats. Significantly lower SOD and CAT levels along with a relatively higher MDA level were observed in the untreated diabetic ED group animals when compared to the normal control group. However, treatment of the diabetic rats with either extract or RA-3 displayed a significantly $(\mathrm{p} \leq 0.001)$ increased SOD and CAT levels in comparison to the untreated diabetic-ED animals. This was accompanied by a significant $(p \leq 0.01)$ decrease in the MDA levels in extract or RA-3 treated groups.

Table 2: Effects of methanol extract on serum antioxidants levels of the diabetic animals.

\begin{tabular}{lccc}
\hline & SOD & CAT & MDA \\
Groups & (Inhibition rate $\%)$ & $(\mathbf{m m o l e s} / \mathbf{m i n} / \mathbf{m l})$ & $(\mathbf{n m o l} / \mathbf{\mu L})$ \\
\hline Normal Control & $66.02 \pm 1.18$ & $1690.7 \pm 295.3$ & $0.03 \pm 0.02$ \\
Diabetic Control & $30.03 \pm 2.01$ & $344.0 \pm 81.2$ & $0.44 \pm 0.04$ \\
Diabetic + Cialis $(5 \mathrm{mg} / \mathrm{kg})$ & $38.88 \pm 1.29$ & $650.7 \pm 83.3$ & $0.32 \pm 0.01$ \\
Diabetic + RA-3 $(100 \mathrm{mg} / \mathrm{kg})$ & $62.08 \pm 2.62^{* *}$ & $1210.7 \pm 88.1 * * *$ & $0.04 \pm 0.00^{* * *}$ \\
Diabetic + Extract $(250 \mathrm{mg} / \mathrm{kg})$ & $65.36 \pm 1.18^{* * *}$ & $1105.3 \pm 109.6^{* * *}$ & $0.09 \pm 0.01 * *$ \\
N. Control + Extract $(250 \mathrm{mg} / \mathrm{kg})$ & $60.82 \pm 0.31$ & $1386.67 \pm 268.4$ & $0.04 \pm 0.01$ \\
\hline
\end{tabular}

\subsection{Effect of the extract on the serum levels of ACE, AChE, arginase and uric acid}

The results of the effect of methanolic roots extract on ACE, AChE and arginase activities accompanied by uric acid levels are presented in Figure 3. A significantly ( $\mathrm{p} \leq$ 0.001 ) higher enzyme activities were observed in the untreated diabetic ED rats when compared with the normal control group. However, administration of the extract to the diabetic ED rats for 28 days, significantly ( $p \leq 0.001$ and $p \leq 0.0001$ ) decreased the enzyme activities when compared to the untreated diabetic ED group. Furthermore, a significant $(p \leq 0.001)$ decreased uric acid level was also observed in the diabetic ED group treated with the extract when compared with an increase uric acid level in the untreated diabetic group.
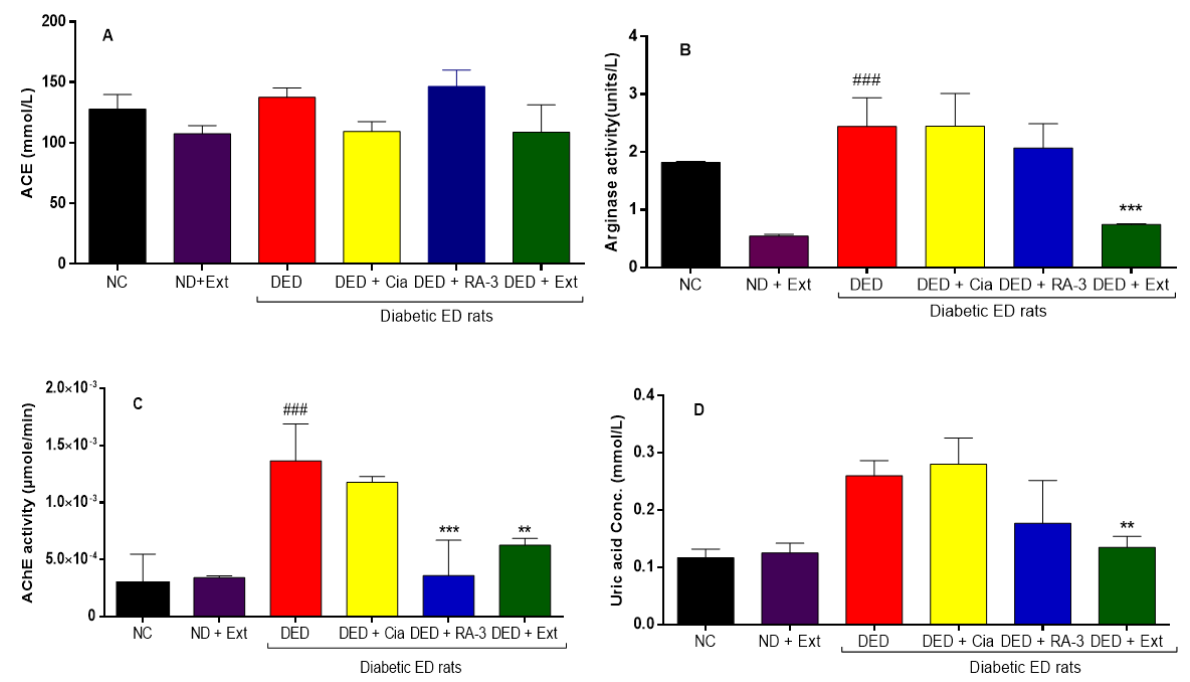
Figure 3. Effect of the methanol extract on ACE (A), arginase (B), AChE (C) activities and uric acid levels (D). Results are expressed as the mean \pm SEM, $(n=5)$. Significant at \#\#\# $p<0.001$ vs. normal control, ${ }^{* * *} \mathrm{p}<0.0001$, and ${ }^{* *} \mathrm{p}<0.001$ vs. Untreated diabetic control. NC - Normal control, $\mathrm{ND}+$ Ext - Nondiabetic + extract, DED - untreated diabetic ED control, DED + Cia - Diabetic + Cialis, DED + RA-3 - Diabetic ED + RA-3, DED + Ext - Diabetic ED + extract

\subsection{Effect of the extract on the expression of PDE-5, RhoA and eNOS}

Effect of the plant extract on the expression of some proteins involved in penile erection process was also investigated. The upregulation of PDE-5 (Figure 4A) and RhoA (Figure $4 \mathrm{C}$ ) accompanied by down regulated eNOS (Figure $4 \mathrm{~B}$ ) were observed in untreated diabetic ED group when compared to normal rats. A significantly lower expression of PDE- 5 and RhoA along with an increased expression of eNOS were observed in the penile tissues of the diabetes induced ED group treated with the extract. Furthermore, a significant decreased expression of PDE- 5 and RhoA in the diabetic ED groups treated with RA-3 and Cialis observed was comparable to nondiabetic animals treated with extract.
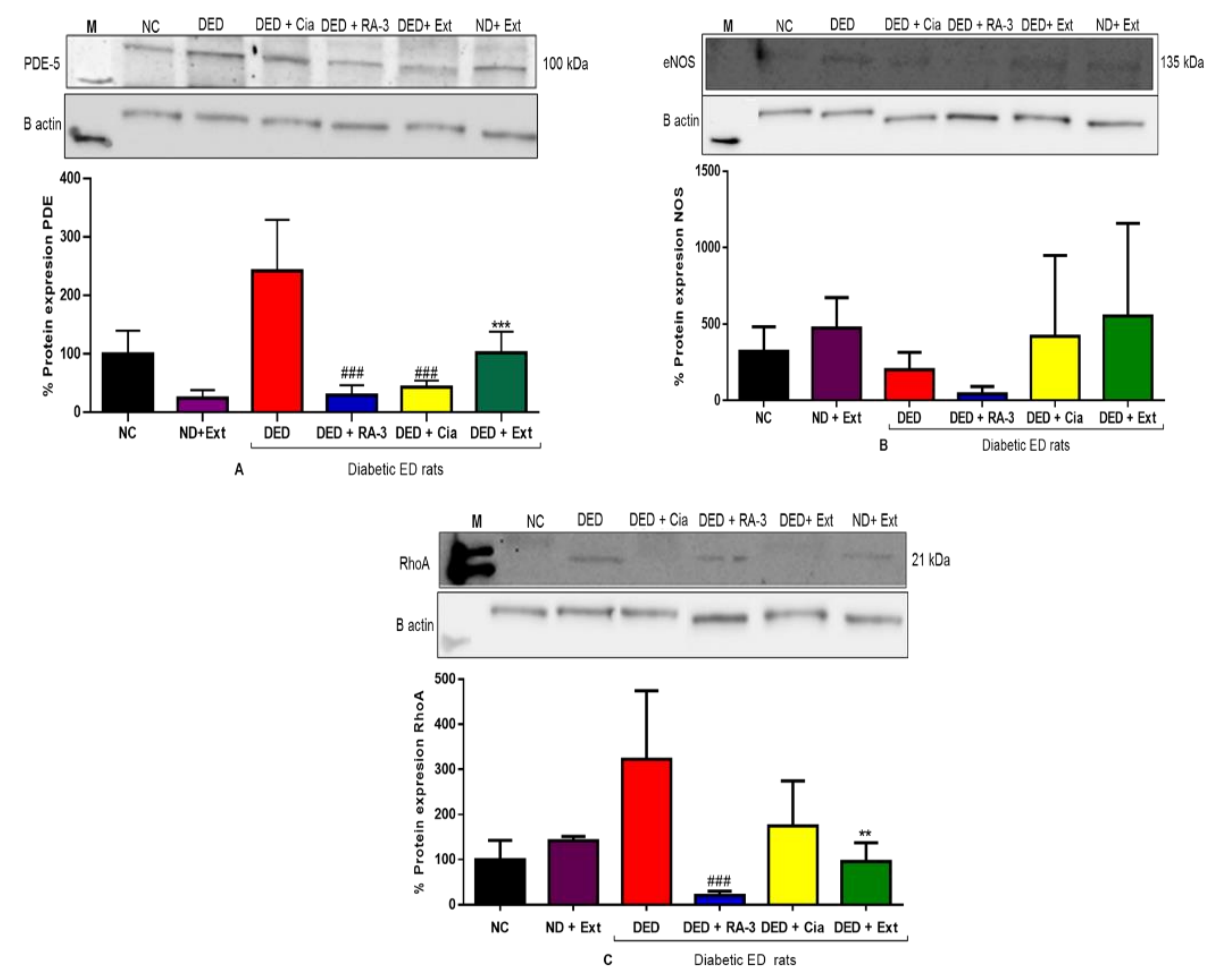

Figure 4. Effect of the methanol extract on PDE-5 (A), eNOS (B) and RhoA (C) expression in type 2 diabetic rats. Values are expressed as the mean $\pm \mathrm{SD}(\mathrm{n}=4) .{ }^{* *} \mathrm{p} \leq 0.01$ vs. diabetic control, $\# \#$ p $\leq 0.001$ vs. diabetic control and normal control. NC - Normal control, ND + Ext - Nondiabetic + extract, DED - diabetic control, DED + Cia - Diabetic ED + Cialis, DED + RA-3 - Diabetic + RA-3, DED + Ext - Diabetic + extract.

\section{Discussion}

The increasing incidence of type 2 diabetes in men contributes to the increasing number of men with ED [1]. An increasing body of evidence supports the use of medicinal plants in the management of diabetes related complications including ED [20, 21]. In this study, the erectogenic effect of the methanolic extract from the roots of the M. procumbens in type 2 diabetic rats is reported. 
The recorded elevated fasting blood glucose in the diabetes induced groups confirmed induction of diabetes state in the animals. While mounting behavior characterizes sexual provocation and penile orientation [1], testosterone regulates nearly every component of erectile function. In addition to increasing sexual desire, testosterone also stimulates synthesis of $\mathrm{NO}$, which activates cascade of reactions leading to vasodilation in the penile tissue [22]. In the present study, the reduced mounting frequency and serum testosterone levels in the model diabetic ED rats indicated a decreased sexual desire/libido, a characteristic of ED. The observed increase in mounting frequency and testosterone levels following treatment of the diabetic rats with the extract indicated the erectogenic potential of the extract. In addition, augmented levels of testosterone and increased mounting frequency observed in the normal animals treated with extract further supported its erectogenic boosting ability.

The decreased serum levels of $\mathrm{AChE}$, arginase and $\mathrm{ACE}$ in the extract treated groups further supported the erectogenic effect of the plant extract. Increased activities of AChE and arginase, commonly observed in diabetic state, diminishes the synthesis and bioavailability of NO, required for efficient penile erection process [23, 24]. Furthermore, the inhibitory effect of the extract on ACE activity, an enzyme that catalyzes the conversion of the angiotensin I to the active vasoconstrictor angiotensin II [25], indicates a potential to ameliorate hypertension-induced ED. Hence, the control of arginase, $\mathrm{AChE}$ and $\mathrm{ACE}$ have been reported as potential therapeutic strategy in the management or treatment of ED [26]. The enzymatic inhibitory activity exhibited by the extract could be attributed to the phytochemical composition of the plant, which includes saponins, tannins and alkaloids. These phytochemicals are known to inhibit the activities of arginase, AChE, ACE and PDE-5 [27-29].

The ability of the plant extract to lower the serum uric acid levels in the extract treated animals further supported its erectogenic potential. Uric acid, an end product of dietary and endogenous purine metabolism, modulate the physiological functions of various physical systems [29]. However, the link between serum uric acid level and ED is still controversial. Various reports have provided evidence that elevated uric acid level is a powerful scavenger of reactive oxygen species (ROS), thus acts as an antioxidant $[30,31]$. Whereas other studies holding the opposite view have revealed that elevated level of uric acid is a potential risk factor of $\operatorname{ED}[32,33]$. In the current study we found that increased level of uric acid is associated with ED (Figure 2.C), hence, the lowered uric acid level observed on the extract treated rats could partly explain its erectogenic property.

Moreover, understanding the molecular mechanisms that underlie the development and progression of ED is also a vital objective in the management and treatment of the ailment. On one hand, PDE-5 hydrolyses cGMP, a second messenger molecule crucial for activating cascade of reactions leading to vasodilation in the penile tissue [34]. On the other hand, RhoA kinase pathway directly suppresses the expression of eNOS, which leads to diminished eNOS activity and reduced bioavailability of NO, thus inhibiting the smooth muscle relaxation and erectile process [35]. The significant downregulation of PDE-5 and RhoA along with an increased expression of eNOS observed in the extract treated group provided support and an insight into the molecular basis of the erectogenic effect of the extract. Our results are similar to those reported by Felaco et al. (2001) and Bivalacqua et al. (2004), who showed the ability of the crude extracts to downregulate RhoA and increase eNOS expression and thus ameliorate erectile dysfunction in diabetes induced ED. Oboh and co-workers, [29] have also shown that downregulation of PDE-5 ameliorates erectile dysfunction in diabetic rats .

The ability of the extract to also lower the fasting blood glucose levels (Table 1) and serum fructosamine (Figure 2A), a substance clinically used as a marker of short-term 
glycemic control in diabetic patients, demonstrated its antihyperglycemic property. The elevated blood glucose levels are known to promote AGEs formation, which accumulate in the corpus cavernosal tissue, particularly in the endothelial and smooth muscle cells, and contribute to the pathogenesis of diabetic ED [36, 37]. AGEs form covalent bonds with vascular collagen, which leads to vascular thickening, reduced elasticity, endothelial dysfunction and increased vascular stiffness [8]. The obtained results from the current work thus show that the crude extract and RA-3 (our in house hyperglycemia control compound [38, 39] partly possesses a comparable hypoglycemic effect when compared to untreated diabetic ED rats and/or Cialis treated animals, respectively.

Chronic elevated blood glucose also induces oxidative stress which underlies various complications of diabetes including endothelial dysfunction and consequent ED development. Increased activity of SOD and CAT accompanied by decreased MDA levels (a measure of lipid peroxidation) in the extract treated diabetic ED group indicated the extract's potential to enhance antioxidant defense system. The increased protein thiol group content in the extract treated diabetic rats (Figure 2B) further indicated the ability of the extract to enhance endogenous antioxidant status. Protein thiol groups are very vulnerable to oxidation and considered as one of the most valuable body sacrificial antioxidants [40]. The antioxidant property of the extract could play a crucial role in ameliorating diabetes induced erectile dysfunction incidence. Various plants with antioxidant properties have been reported to improve erectile function in diabetic-ED rats [26, 27].

\section{Materials and Methods}

\subsection{Chemicals and reagents}

All chemicals and reagents used in this study were of analytical quality and all were purchased from Sigma-Aldrich Chemical Co., St. Louis, MO, USA.

\subsection{Methods}

\subsubsection{Extract preparation}

Maytenus procumbens roots were collected from Ndumo and confirmed by a qualified botanist at the Botany Department, University of Zululand, KwaZulu Natal, South Africa. The roots were thoroughly washed, chopped, air dried and ground into powder. The powdered plant material was extracted $(1: 5 \mathrm{w} / \mathrm{v})$ with methanol to obtain methanolic crude extract. Thereafter, the methanolic extract was filtered through Whatman No. 1 filter paper. The methanol extract was then concentrated under reduced pressure at $40{ }^{\circ} \mathrm{C}$ using a rotary evaporator (Heidolph). The crude extract was then ready to be used for the biological assays.

\subsubsection{Animals}

Ethical clearance (UZREC 171110-030 PGD 2018/230) for approval of procedures and use of laboratory animals was obtained from the University of Zululand Research Ethics Committee (UZREC). Sprague-Dawley rats (06-12 weeks of age) were obtained from the laboratory animal unit of Biochemistry and Microbiology Department, University of Zululand. Rats were kept under standard laboratory conditions (at $23 \pm 2{ }^{\circ} \mathrm{C}, 60 \%$ humidity and day-night cycle under light) as outlined in the institutional and national guidelines for handling and caring of science laboratory animals. The rats were allowed to acclimatize for at least five days with free access to enough normal rat feed and drinking water before the experiment commenced. 


\subsubsection{Induction of type 2 diabetes}

Type 2 diabetes was induced using the method previously described by Pereira et al. (2014) with some modifications. Briefly, Sprague Dawley rats were randomly divided into two major groups; normal group (normal diet and drinking tap water) and high fructose fed group (normal diet and $25 \%$ of fructose in drinking water). The animals were put of high fructose for a period of 120 days. After 120 days, the high fructose fed group rats were fasted overnight and they were then given an intraperitoneal injection of a low single dose $(30 \mathrm{mg} / \mathrm{kg})$ of a freshly prepared streptozotocin (STZ) solution. After five days of the STZ injection, blood glucose levels were measured with a glucometer (Accutrend glucometer; Roche Diagnostics, Mannheim, Germany) from the blood collected from the tail tip. Animals with blood glucose levels equal to or above $09 \mathrm{mmol} / \mathrm{L}$ were considered diabetic and used in the study.

\subsubsection{Investigation of the erectogenic effect of the plant extract}

At the end of the induction of T2D, estrous was induced in a group of female rats $(150-200 \mathrm{~g})$. These female rats received three consecutive subcutaneous injections of progesterone $(7.5 \mathrm{mg} / \mathrm{kg}$, at 24-hour intervals) 96 hours before being introduced to male rats for determination of baseline sexual behavior of the male rats. After that, the normal group was subdivided into two groups while the diabetic group was also subdivided into four groups of five rats per group as shown in Figure 1.

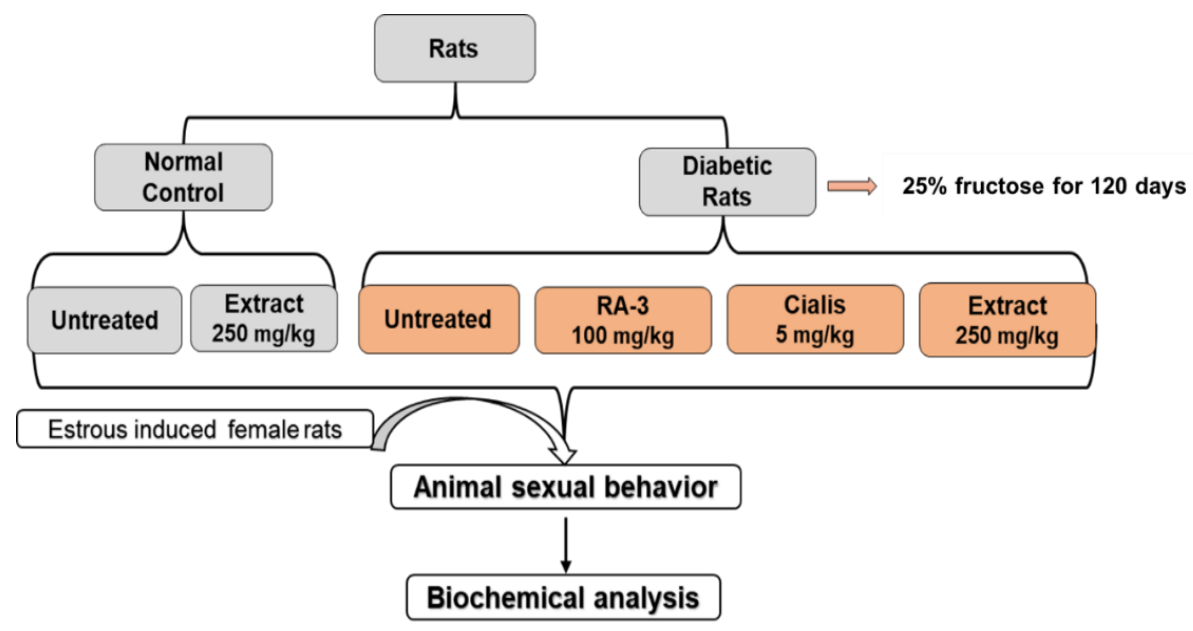

Figure 1. Schematic representation of the erectogenic effect of the methanolic roots extract on type 2 diabetic rats.

Thereafter, the experimental groups were orally administered daily with the extract at $250 \mathrm{mg} / \mathrm{kg}$ b.w for 28 days. Normal control and negative control (Diabetic ED control) received a carrier solvent while positive controls received an indoor control RA-3 (100 $\mathrm{mg} / \mathrm{kg} \mathrm{b.w}$ ) and Cialis ( $5 \mathrm{mg} / \mathrm{kg} \mathrm{b.w})$, respectively. Thereafter, estrous induced group of female rats (induced as described above), were then introduced to male rats for sexual animal behavior, each male rat from various treatment groups was individually subjected to the estrous female rats $(n=3)$ in a separate cage for 30 minutes and the number of mounts was recorded.

\subsubsection{Biochemical analysis}

At the end of the experimental period, all the male rats were fasted for 8 hours and euthanized under anaesthesia. The loss of sensation was confirmed by the pedal withdrawal reflex and assessed by pinching of the tails, prior to blood collection. Blood was 
immediately collected by cardiac puncture and the penile tissues as well as brains were removed for analysis of significant biochemical assay. The collected blood was allowed to clot and centrifuged for 10 minutes at $3,500 \mathrm{rpm}$ at $4{ }^{\circ} \mathrm{C}$, and serum was collected. The brains were weighed and homogenized in $0.1 \mathrm{M}$ phosphate buffer saline ( $\mathrm{pH}$ 8.0). The serum levels of some antioxidants (SOD, CAT), MDA content, arginase and ACE activities as well as AChE activity from brain supernatant were estimated using respective commercial activity assay kits (Sigma-Aldrich), suitable for rat samples, following manufacturers' instructions. The serum testosterone, and uric acid levels were determined using standard laboratory procedures (Global Laboratory \& Viral Laboratory, Richards Bay).

\subsubsection{Estimation of serum fructosamine concentration}

Fructosamine concentration was determined in the serum of the rats using nitro-blue tetrazolium (NBT) assay as previously described by Adisakwattana et al. [19]. Briefly, $125 \mu \mathrm{l}$ of serum samples from the different groups was incubated with $125 \mu \mathrm{l}$ of $0.5 \mathrm{mM}$ NBT in $0.1 \mathrm{M}$ sodium carbonate buffer $(\mathrm{pH} 10.4)$ at $37^{\circ} \mathrm{C}$ for 15 minutes. The absorbance was measured at the wavelength of $590 \mathrm{~nm}$. The concentration of fructosamine $(\mathrm{mg} / \mathrm{ml})$ in the respective samples was determined from the standard curve of 1-deoxy-1-morpholino-fructose (1-DMF).

\subsubsection{Determination of protein thiol group}

The Ellman's assay was used to also determine the level of protein thiol groups [19]. The serum samples $(125 \mu \mathrm{l})$ from different groups were incubated with $125 \mu \mathrm{l}$ of 5 $\mathrm{mM}$ 5,5'-Dithiobis (2-nitrobenzoic acid, DTNB) solution for 15 minutes at $37^{\circ} \mathrm{C}$, followed by measuring the absorbance at the wavelength of $410 \mathrm{~nm}$. The free thiol concentration of samples was calculated based on the standard curve prepared by using various concentration of L-cysteine.

\subsubsection{Western blot analysis}

Western blot analysis of some proteins involved in the erection process were performed. Snap frozen penile muscle tissue $(100 \mathrm{mg})$ was defrosted on ice and lysed in lysis buffer (Pierce Biotechnologies, Rockford, CA, USA) using a Tissue lyser. Thereafter, the samples were centrifuged for 15 minutes at $13,000 \mathrm{rpm}$ at $4{ }^{\circ} \mathrm{C}$. Supernatant was collected and stored at $-20^{\circ} \mathrm{C}$ until required for use. Protein sample was mixed with an equal volume of $2 \mathrm{x}$ Laemmli sample buffer before it was denatured at $95{ }^{\circ} \mathrm{C}$ for 5 minutes. The denatured protein samples $(30 \mu \mathrm{g})$ were loaded on the $12 \%$ SDS-polyacrylamide gel (Bio-Rad, Hercules, CA, USA) and run for 1 hour at $150 \mathrm{~V}$ in Tris/Glycine/SDS-PAGE Buffer 1X. The proteins from the gel were then transferred to the polyvinylidene fluoride membrane (PVDF) (Bio-Rad, Hercules, CA, USA) (Johnson et al., 2017). The membranes (containing the proteins) were incubated at $4{ }^{\circ} \mathrm{C}$ for 16 hours with the following primary antibodies: anti- PDE-5 (1:500), RhoA (1:500) and eNOS (1:10000) (Sigma-Aldrich Chemical Co., St. Louis, MO, USA). The membranes were washed and incubated with the appropriate horseradish peroxidase conjugated secondary antibody at room temperature for 90 minutes. All proteins were normalized to a loading control ( $\beta$-Actin) (1:500) (Santa Cruz Biotechnology, Dallas, TX, USA). Chemidoc-XRS imager and image lab version 06 software (Bio-Rad Laboratories, Hercules, CA, USA) was used to Detect and quantify the proteins.

\subsubsection{Statistical analysis}

Results are presented as the mean \pm standard error of the mean (mean \pm SEM) in triplicates. Statistical analysis of the differences between mean values obtained from 
experimental groups were calculated using GraphPad prism (v6.01). Data were subjected to one-way analysis of variance (ANOVA) followed by Dunnett's multiple comparison test. $\mathrm{p} \leq 0.05$ was regarded as statistically significant.

\section{Conclusions}

The present study provides evidence that methanolic roots extract of the Maytenus procumbens ameliorates diabetes induced erectile dysfunction, suggesting that the plant could potentially be used in the management of diabetic ED. The ameliorative effects of the extract were due to an increased testosterone levels and mount frequency accompanied by inhibitory effect on arginase, ACE and AChE activities in the diabetic ED treated group. In addition, the mechanism through which the extract exerts its erectogenic potential could be attributed to its ability to downregulate PDE-5 and RhoA accompanied by upregulated eNOS. Nevertheless, the effect of the extract on smooth muscle contraction and the histopathological analysis of the penile tissue from the diabetic induced ED in rats is recommended to confirm the its erectogenic potential.

Author Contributions: RAM \& ARO designed and supervised the project; NDC performed the experiments and wrote the manuscript; SEMM, TN, SEM \& KZ experimental designed and interpretation of western blot analysis. Also, they all contributed in the writing of the manuscript.

Funding: The study received funding from the University of Zululand Research Committee. The authors are grateful to NRF-South Africa for funding ND Cele and the team of South African Medical Research Council (SAMRC) for their technical assistance.

\section{Conflict of interest}

The authors declare no conflict of interest. The funding sponsors had no role in the design of the study; in the collection, analyses, or interpretation of data; in the writing of the manuscript and in the decision to publish the results.

\section{References}

1. 1. Minaz, N., et al., Impact of diabetes on male sexual function in streptozotocin-induced diabetic rats: protective role of soluble epoxide hydrolase inhibitor. Biomedicine \& Pharmacotherapy, 2019. 115: p. 108897.

2. 2. Kaya, E., S.C. Sikka, and S. Gur, A comprehensive review of metabolic syndrome affecting erectile dysfunction. The journal of sexual medicine, 2015. 12(4): p. 856-875.

3. 3. Ribeiro, S., et al., General practitioners' procedures for sexual history taking and treating sexual dysfunction in primary care. The journal of sexual medicine, 2014. 11(2): p. 386-393.

4. 4. Bossio, J.A., et al., Mindfulness-based group therapy for men with situational erectile dysfunction: A mixed-methods feasibility analysis and pilot study. The journal of sexual medicine, 2018. 15(10): p. 1478-1490.

5. 5. Laumann, E.O., et al., A population-based survey of sexual activity, sexual problems and associated help-seeking behavior patterns in mature adults in the United States of America. International Journal of Impotence Research, 2009. 21(3): p. 171-178.

6. 6. Thakur, M., S. Bhargava, and V. Dixit, Effect of Asparagus racemosus on sexual dysfunction in hyperglycemic male rats. Pharmaceutical Biology, 2009. 47(5): p. 390-395.

7. 7. Georgiadis, G., et al., Current concepts on the reno-protective effects of phosphodiesterase 5 inhibitors in acute kidney injury: systematic search and review. Journal of clinical medicine, 2020. 9(5): p. 1284.

8. 8. Singh, R., et al., Advanced glycation end-products: a review. Diabetologia, 2001. 44(2): p. 129-146.

9. 9. Ademiluyi, A.O., et al., Effect of fermented legume seeds on some key enzymes relevant to erectile dysfunction in vitro. Journal of Food Biochemistry, 2018. 42(4): p. e12437.

10. 10. Tsai, E.J. and D.A. Kass, Cyclic GMP signaling in cardiovascular pathophysiology and therapeutics. Pharmacology \& therapeutics, 2009. 122(3): p. 216-238.

11. 11. Shah, N., et al., Muscarinic receptors and ligands in cancer. American Journal of Physiology-Cell Physiology, 2009. 296(2): p. C221-C232.

12. 12. Zeng, G. and M.J. Quon, Insulin-stimulated production of nitric oxide is inhibited by wortmannin. Direct measurement in vascular endothelial cells. The Journal of clinical investigation, 1996. 98(4): p. 894-898.

13. 13. Muniyappa, R., M. Iantorno, and M.J. Quon, An integrated view of insulin resistance and endothelial dysfunction. Endocrinology and metabolism clinics of North America, 2008. 37(3): p. 685-711.

14. 14. Goswami, S.K., et al., Screening for Rho-kinase 2 inhibitory potential of Indian medicinal plants used in management of erectile dysfunction. Journal of ethnopharmacology, 2012. 144(3): p. 483-489.

15. 15. Corona, G., et al., Sexual dysfunction in type 2 diabetes at diagnosis: progression over time and drug and non-drug correlated factors. PloS one, 2016. 11(10): p. e0157915. 
16. 16. Kizilay, F., H.E. Gali, and E.C. Serefoglu, Diabetes and sexuality. Sexual medicine reviews, 2017. 5(1): p. 45-51.

17. 17. Momtaz, S., et al., Growth inhibition and induction of apoptosis in human cancerous HeLa cells by Maytenus procumbens. Food and chemical toxicology, 2013. 51: p. 38-45.

18. 18. Cele, N.D., et al., Testicular Dysfunction Ameliorative Effect of the Methanolic Roots Extracts of Maytenus procumbens and Ozoroa paniculosa. Evidence-Based Complementary and Alternative Medicine, 2017. 2017.

19. 19. Adisakwattana, S., et al., Cinnamic acid and its derivatives inhibit fructose-mediated protein glycation. International journal of molecular sciences, 2012. 13(2): p. 1778-1789.

20. 20. Adefegha, S.A., et al., Comparative effects of alkaloid extracts from Aframomum melegueta (Alligator pepper) and Aframomum danielli (Bastered melegueta) on enzymes relevant to erectile dysfunction. Journal of dietary supplements, 2017. 14(5): p. 542-552.

21. 21. Ademosun, A.O., A.A. Adebayo, and G. Oboh, Anogeissus leiocarpus attenuates paroxetine-induced erectile dysfunction in male rats via enhanced sexual behavior, nitric oxide level and antioxidant status. Biomedicine \& Pharmacotherapy, 2019. 111: p. 1029-1035.

22. 22. Vudriko, P., et al., Crude ethanolic leaf extracts of Citropsis articulata: A potential phytomedicine for treatment of male erectile dysfunction associated with testosterone deficiency. Int. J. Basic Clin. Pharmacol, 2014. 3(1): p. 120-123.

23. 23. Corbin, J., Mechanisms of action of PDE5 inhibition in erectile dysfunction. International journal of impotence research, 2004. 16(1): p. S4-S7.

24. 24. Vargas, V., et al., Cholinergic facilitation of erection and ejaculation in spinal cord-transected rats. International journal of impotence research, 2004. 16(1): p. 86-90.

25. 25. John, S. and R.E. Schmieder, Potential mechanisms of impaired endothelial function in arterial hypertension and hypercholesterolemia. Current hypertension reports, 2003. 5(3): p. 199-207.

26. 26. Akomolafe, S.A., et al., Phenolic characterization, antioxidant activities, and inhibitory effects of Physalis angulata and Newbouldia laevis on enzymes linked to erectile dysfunction. International Journal of Food Properties, 2018. 21(1): p. 645-654.

27. 27. Ojo, O.A., et al., Ocimum gratissimum Linn. Leaves reduce the key enzymes activities relevant to erectile dysfunction in isolated penile and testicular tissues of rats. BMC complementary and alternative medicine, 2019. 19(1): p. 1-10.

28. 28. Odubanjo, V.O., et al., Seed extracts from Myristica fragrans (Nutmeg) and Moringa oleifera (Drumstick tree) inhibits enzymes relevant to erectile dysfunction and metal-induced oxidative damage in rats' penile tissues. Journal of Food Biochemistry, 2018. 42(1): p. e12452.

29. 29. Oboh, G., et al., Aphrodisiac effect of Hunteria umbellata seed extract: Modulation of nitric oxide level and arginase activity in vivo. Pathophysiology, 2019. 26(1): p. 39-47.

30. 30. Waring, W.S., et al., Uric acid restores endothelial function in patients with type 1 diabetes and regular smokers. Diabetes, 2006. 55(11): p. 3127-3132.

31. 31. Fabbrini, E., et al., Effect of plasma uric acid on antioxidant capacity, oxidative stress, and insulin sensitivity in obese subjects. Diabetes, 2014. 63(3): p. 976-981.

32. 32. Chaudhari, K., et al., Clinical correlation of alteration of endogenous antioxidant-uric acid level in major depressive disorder. Indian Journal of Clinical Biochemistry, 2010. 25(1): p. 77-81.

33. 33. Barassi, A., et al., Levels of uric acid in erectile dysfunction of different aetiology. The Aging Male, 2018. 21(3): p. 200205.

34. 34. Oboh, G., et al., In vitro inhibition of phosphodiesterase-5 and arginase activities from rat penile tissue by two Nigerian herbs (Hunteria umbellata and Anogeissus leiocarpus). Journal of basic and clinical physiology and pharmacology, 2017. 28(4): p. 393-401.

35. 35. Chitaley, K., et al., Antagonism of Rho-kinase stimulates rat penile erection via a nitric oxide-independent pathway. Nature medicine, 2001. 7(1): p. 119-122.

36. 36. Seftel, A.D., et al., Advanced glycation end products in human penis: elevation in diabetic tissue, site of deposition, and possible effect through iNOS or eNOS. Urology, 1997. 50(6): p. 1016-1026.

37. 37. Sandireddy, R., et al., Neuroinflammation and oxidative stress in diabetic neuropathy: futuristic strategies based on these targets. International journal of endocrinology, 2014. 2014.

38. 38. Mosa, R.A., et al., In vivo antihyperglycemic activity of a lanosteryl triterpene from Protorhus longifolia. Molecules, 2015. 20(7): p. 13374-13383.

39. 39. Mabhida, S.E., et al., A lanosteryl triterpene from Protorhus longifolia improves glucose tolerance and pancreatic beta cell ultrastructure in type 2 diabetic rats. Molecules, 2017. 22(8): p. 1252.

40. 40. SMITH, P.R. and P.J. THORNALLEY, Mechanism of the degradation of non-enzymatically glycated proteins under physiological conditions: Studies with the model fructosamine, Ne-(1-deoxy-d-fructos-1-yl) hippuryl-lysine. European Journal of Biochemistry, 1992. 210(3): p. 729-739. 